\title{
Review paper on Blue Brain Technology
}

\author{
Mannu Kumari \\ Scholar, ABES Institute of Technology, \\ Ghaziabad, India
}

\author{
Rizwan Khan \\ Associate Professor, ABES Institute of \\ Technology, Ghaziabad, India
}

\begin{abstract}
The brain is one of the most unique and brilliant organ in the human body. Our brain gives us awareness of everything including ourselves and our environment. It controls movements of the muscles, the glands secretions, and even internal temperature and breathing. Every thought, reaction, and idea is developed by our brain. The brain's neurons record all the memory of every action in our lives. The man is called "intelligent" because of brain but when the body is destroyed after the death, it is lost. Today scientists are in research to create a virtual brain. Here we describe how the intelligence can be preserved for thousands of years.
\end{abstract}

\section{Keywords}

Blue Brain, Artificial Intelligence, Human Brain, Nanobots, Blue Gene, Neural Networks

\section{INTRODUCTION}

Blue Brain is an artificial brain which can think, take decisions, and respond as a natural brain.

The most important question that arises here is that "Is it possible to create a human brain?"

Yes It is possible with the help of technology because everything that is created by man today, he always followed the nature. So, a super computer with high amount of storage capacity, processing power and an interface between the human brain and this virtual one can be used for creating it. This is not happening today or tomorrow. But we are expecting this in near future. If we finally achieve this then even after death of human body we preserve his knowledge and intelligence. It is the latest invention in the field of neural network. This technology opens new door in the field of artificial intelligence. It provides comprehensive simulation of the internal connectivity of cerebral part with the external artificial intelligence network.

\section{BLUE BRAIN}

The BLUE BRAIN is a reverse engineering project of recreation of the human brain. The project is headed by the founding director Henry Markram, who also heads the European Human Brain Project, and co-directed by Felix Schürmann and Sean Hill. IBM is now in research to invent a virtual brain that can function as a human brain, called BLUE BRAIN. If possible, then it would be the first virtual brain of the world. Within coming years, we will be able to scan ourselves into the computers.

The goals of this project are:
i)
To gain complete understanding of the brain
ii) Better and faster development of brain disease treatments.

\section{AIM OF BLUE BRAIN}

The main aim of Blue Brain is to transfer human brain into machine. So that, without any effort a man can think and take decisions. Today scientists are in research to invent an artificial brain that can response, take decision, think, and keep anything in memory for longer period of time. Different actions and structure of our CNS i.e., central nervous system can also be studied.

\section{NEED OF BLUE BRAIN}

'Intelligence' is the quality that cannot be transferred or created and by which all of us are differentiated. Some people have very high level of intelligence like Einstein etc but after the death along with their body their intelligence is also lost. Sometimes we face difficulties in remembering things like names, spellings, important dates, facts etc. By having a machine to assist all these in our busy life, we will be relaxed.

The one solution to all these is "Virtual Brain" with the help of which the brain and intelligence will be alive even after the death.

\section{HUMAN BRAIN WORKING}

The ability of human to see, interpret, feel is controlled by our nervous system. The human brain is the command center for the nervous system.

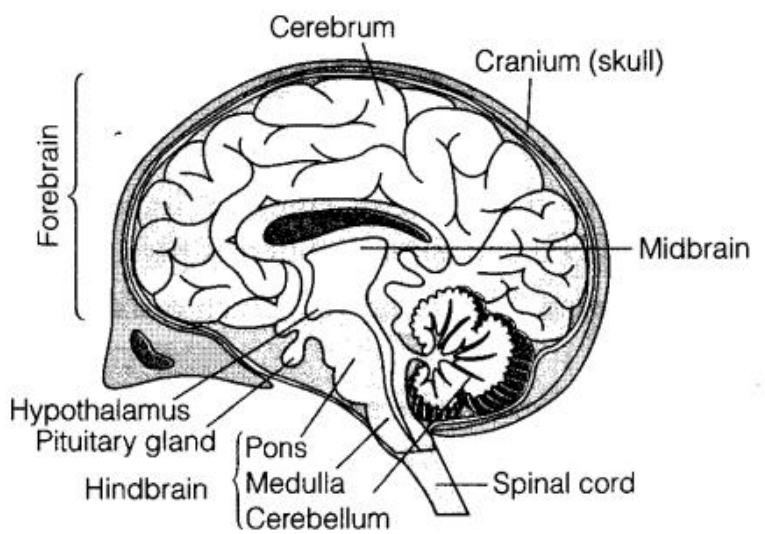

Fig-1: Structure of Human Brain

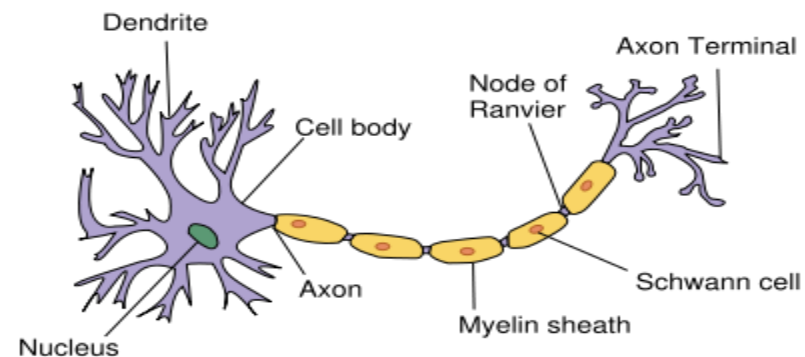

Fig-2: Structure of Neuron

There are basically three steps in the functioning of brain:
i. Sensory Input
ii. Integration/ Interpretation
iii. Motor Output 

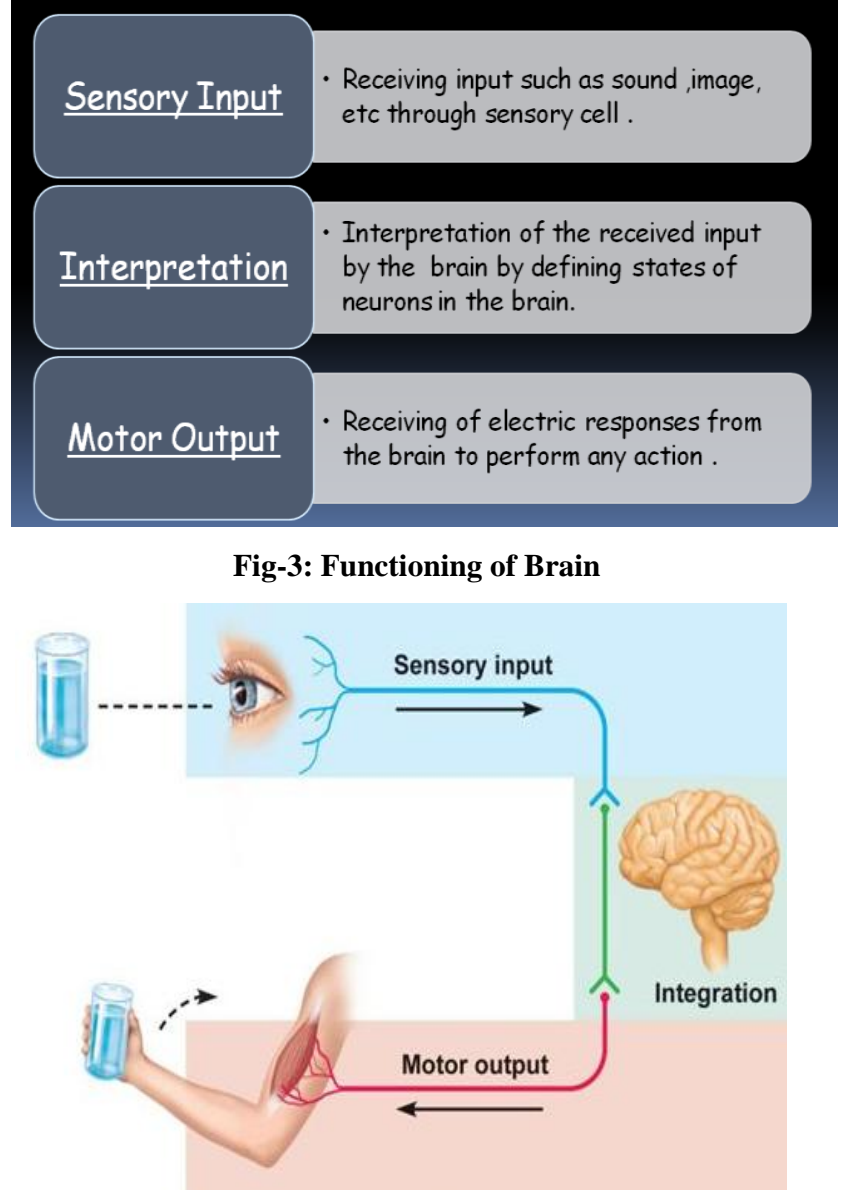

Fig-4: Functioning of Nervous System

\section{BRAIN SIMULATION}

Table-1 Brain Simulation

\begin{tabular}{|c|l|l|}
\hline Input & Natural Brain & Simulated Brair \\
\hline Interpretation & $\begin{array}{l}\text { Through the natural } \\
\text { neurons. }\end{array}$ & $\begin{array}{l}\text { Through the silicon chi } \\
\text { or artificial neurons. }\end{array}$ \\
\hline neurons in the brain. & $\begin{array}{l}\text { By set of bits in set of } \\
\text { registers. }\end{array}$ \\
\hline Processing & $\begin{array}{l}\text { Through arithmetic and } \\
\text { logical calculations. }\end{array}$ & $\begin{array}{l}\text { Through arithmetic, } \\
\text { logical calculation \& AI. }\end{array}$ \\
\hline Memory & $\begin{array}{l}\text { Through permanent } \\
\text { states of neurons. }\end{array}$ & $\begin{array}{l}\text { Through secondary } \\
\text { memory. }\end{array}$ \\
\hline Output & $\begin{array}{l}\text { Through the natural } \\
\text { neurons. }\end{array}$ & $\begin{array}{l}\text { Through the silicon } \\
\text { chip. }\end{array}$ \\
\hline
\end{tabular}

\section{STEPS TO BUILD A BLUE BRAIN}

There are basically 3 steps to build a Blue Brain.

\section{Data Acquisition :-}

In this step, all the data from brain is collected and after being analyzed under a microscope, we can understand the electrical behavior individually of the neurons. For further simulation, observations are transformed into algorithms.

\section{Data Simulation :-}

In this step, mathematical models are used to recreate various situations to estimate the outcomes more accurately.
There are 2 aspects of simulation-

i) Speed of simulation:

The speed of simulation is 200 times slower than the real one.

ii) Simulation Workflow:

In simulation step, virtual cells are synthesized by using the algorithms.

\section{Visualization of Results}

For the visualization of the neural simulations RTNeuron are generally used. This software is written in C++ and OpenGL. It basically gives the output in 3D.

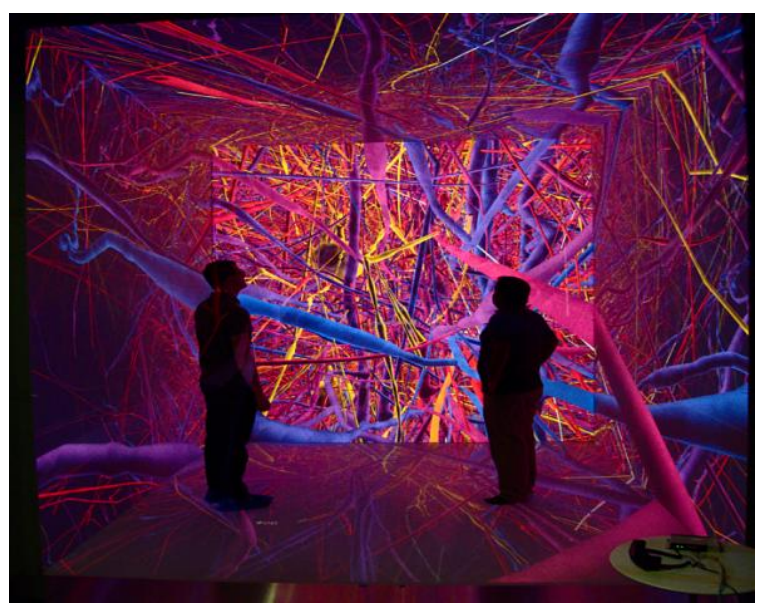

Fig-5 RT Neuron visualization of a neuron

\section{UPLOADING HUMAN BRAIN}

A research paper is provided by Raymond Kurzweil on this topic. In which he stated that the uploading of human brain into the computer can be done by the use of small robots known as the Nanobots. These robots can travel all over our circulatory system as they are very small. They can even monitor all the activities going on in our body and structure of CNS. They can provide complete readout of the structure of our brain and connection by scanning it. These information can be saved into a computer and then continue to work as the human brain.

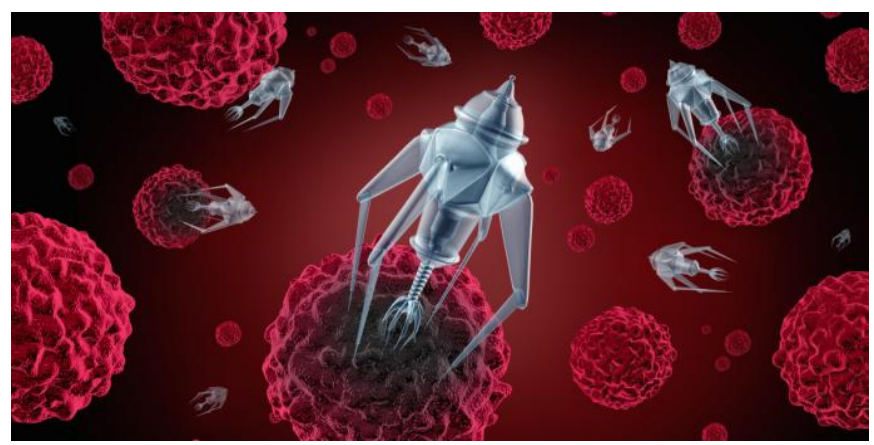

Fig-6 Nanobots

\section{BARRIERS IN BUILDING OF BLUE BRAIN}

Currently, there is some barrier in the neuron connectivity with artificial neuron. To solve this barrier, it will take more than four years. Once it is established then we require five or more years to complete Blue Brain project. By Adapting methodology of nanobots, there will be decrease in development time and lead to better performance. Thus, we 
can say that Blue Brain can be implemented in future with some advancement in technology.

\section{COMPUTER HARDWARE/ SUPER COMPUTERS}

The "Blue Gene" supercomputer built by IBM is used for the development of Blue Brain. This is where the name "Blue Brain" originates from. The series includes Blue Gene/L, Cyclops64, (formerly Blue Gene/C), Blue Gene/P and Blue Gene/Q.

The hardware \& software required to build a Blue Brain are:
i. $\quad 8,096 \mathrm{CPUs}$ at $700 \mathrm{MHz}$
ii. $256 \mathrm{MB}$ to $512 \mathrm{MB}$ memory per processor.
iii. 100 kilowatts power consumption.
iv. Processor with a very high processing power.
v. $\quad 22.8$ TFLOPS peak processing speed.
vi. Linux and $\mathrm{C}++$ software

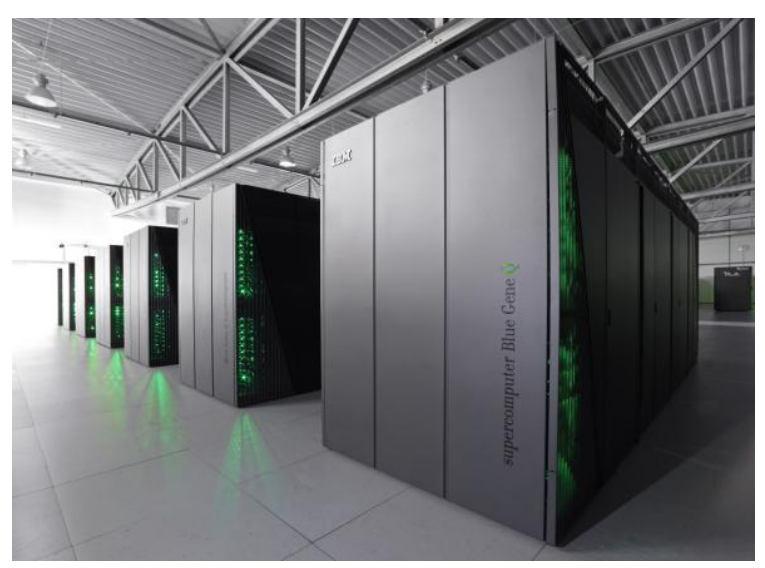

Fig-7 Blue Gene Supercomputer

\section{POSITIVE EFFECTS OF BLUE BRAIN}

i. Remembering things without any effort is possible.

ii. We can make decisions without the physical existence of a person.

iii. Usage of the intelligence of a person after his/her death.

iv. The actions of animals can be understood easily.

v. Via direct nerve stimulation, the deaf is able to hear.

\section{NEGATIVE EFFECTS OF BLUE}

\section{BRAIN}

i. We will more rely on computer.

ii. Technical knowledge can be used against us.

iii. There are more power constraints as the supercomputers may use as much as $1 \mathrm{MW}$ or an order of 100,000 more.

iv. Human Cloning is also possible.

\section{FUNCTIONS OF BLUE BRAIN}
i. Data of 100 years can be gathered, stored and tested
ii. Cracking of Neural code.
iii. Process of Neocortical information can be easily understood.
iv. Complete brain simulations.
v. Brain function molecular modeling.

\section{CONCLUSION}

Hence, we can say that with some improvement in today's technology, the Blue Brain can be implemented in future and transferring ourselves into computer would be possible. The intelligence of human brain will be stored even after the death for betterment of society. We can make decisions without the actual presence of a person. But it is also true that we will depend on the computer. It will bring both positive and negative effects to human society. This technology will be accepted all over the world widely very soon.

\section{REFERENCES}

[1] Priya Babel, Blue Brain - The Future Generation, Research Journal of Computer and Information Technology Sciences ISSN 2320 - 6527 Vol. 3(2), 1-5, May (2015)

[2] Ms Akanksha V. Patil, Ms. Ruchita R. Kesarkar, Mrs. Sapana G. Buwa, Ms. Jyotsna T. Kumbhar, Mr. Vijay U. Patil, BLUE BRAIN, IRACST - International Journal of Computer Science and Information Technology \& Security (IJCSITS), ISSN: 2249-9555 Vol. 2, No.6, December 2012

[3] Mythili.M, Nandhini.S, A Study on Artificial Intelligence- The Blue Brain, International Journal of Innovative Research in Computer and Communication Engineering Vol. 4, Issue 8, August 2016

[4] Iyer Mili Venkat, Sachin Gala, Ruchik Thakkar, Manan Mehta, Yash Bhawre, Blue Brain: Bringing a Virtual Brain to Life, International Journal on Recent and Innovation Trends in Computing and Communication Volume: 4 Issue: 1

[5] Ms. K. Kaviya, THE BLUE BRAIN, IJAICT Volume 1 , Issue 3, July 2014

[6] Siva Kumar Avula, Vedrucha S Pakale and Sheetal V Kashid, Blue Brain - The Future Generation, International Journal of Application or Innovation in Engineering \& Management (IJAIEM) Volume 2, Issue 3, March 2013

[7] S. Mondal, S. Parvin, S. F. Ahmmed, BLUE BRAIN ADVANCE TECHNOLOGY, International Journal of Engineering and Techniques - Volume 1 Issue 1, 2015

[8] Surya Verma, Bhumika Kohli, Blue Brain, International Journal of Scientific and Research Publications, Volume 5, Issue 10, October 2015

[9] http://www.artificialbrains.com/blue-brain-project

[10] https://en.wikipedia.org/wiki/Blue_Brain_Project 